\title{
Patient satisfaction and early geriatric follow-up after discharge in older acute medical patients
}

\author{
Merete Gregersen*1, Anita Haahr ${ }^{2}$, Lene Holst Pedersen ${ }^{1}$, Else Marie Damsgaard ${ }^{1}$ \\ ${ }^{1}$ Department of Geriatrics, Aarhus University Hospital, Aarhus, Denmark \\ ${ }^{2}$ VIA University College, Aarhus, Denmark
}

Received: May 31, 2016

DOI: $10.5430 /$ cns.v4n3p78
Accepted: June 25, 2016

Online Published: June 30, 2016

\begin{abstract}
Objective: "Early geriatric follow-up after discharge" is a care model designed to create a safe transition from hospital to home by adding a follow-up visit in the patient's home within 24 hours after discharge. Patient satisfaction is of major importance to evaluate health care services. Therefore, the aim of this study was to compare patient satisfaction after early geriatric follow-up with that of usual follow-up after discharge.

Materials and methods: The study is a cross-sectorial quantitative questionnaire survey. The target population was 75+ years' medical patients acutely admitted to an emergency department (ED) and enrolled in a quasi-randomized controlled trial. A 14-item satisfaction questionnaire, based on semi-structured interviews, was mailed to all cognitively well-functioning patients in both groups 2-4 weeks after discharge during three defined time periods. The themes of importance were: feeling safe, receiving sufficient information, experiencing good communication between health care professionals, involvement in care decisions, and relatives' involvement. Each question was evaluated by a 5-point Likert scale. The patients, who did not respond within 14 days, were reminded by phone and offered assistance to fill out the questionnaire.

Results: In total, 173 out of 272 patients (64\%) returned their questionnaire. Baseline characteristics of the groups were similar. More patients in the intervention group (receiving early geriatric follow-up after discharge) were "satisfied with treatment and care after discharge" and were "satisfied with the continuity of care at home" compared to the patients in the control group (receiving usual follow-up). More women were non-responders than men.

Conclusions: Older medical patients acutely admitted to hospital were more satisfied with early geriatric follow-up than usual follow-up after discharge.
\end{abstract}

Key Words: Patient satisfaction, Geriatrics, follow-up, Home care, Questionnaire, Hospital at home

\section{INTRODUCTION}

Older people are vulnerable to adverse incidents, that leave them as large consumers of health-care services. ${ }^{[1,2]}$ There is a growing interest in the services to shorten hospital stay and to prevent readmissions after discharge. "Early geriatric follow-up after discharge" is a multidisciplinary model designed to create a safe transition by adding a follow-up visit in the patient's home within 24 hours after hospital discharge. This has proven to be able to reduce the length of hospital stay and the number of acute readmissions. ${ }^{[3]}$ Hospital care in the patient's home is as effective and safe as inpatient care. ${ }^{[4]}$ Older patients place great importance on staying at home and regard hospital stay as undesirable, although necessary if their medical condition requires it. The

*Correspondence: Merete Gregersen; Email: meregreg@rm.dk; Address: Department of Geriatrics, Aarhus University Hospital, Aarhus, Denmark. 
elements leading to dissatisfaction during hospitalization are separation from spouse, impersonal care from nurses, poor communication with doctors, and understaffing. ${ }^{[5]}$

Patient satisfaction is used as one of the methods to evaluate the quality of hospital service from the patient's perspective. The questionnaire is an important and useful tool to gather valid data from a representative sample of respondents. ${ }^{[6]}$ In meta-analyses, patients with medical illness have reported increased satisfaction with "early discharge hospital at home" compared with "usual hospital care" ${ }^{[7,8]}$ The majority of these patients had very positive experiences, citing good communication, frequent and timely visits, and attention to details as positive aspects of the hospital service. However, the studies on patient satisfaction are mainly based on qualitative interviews and are difficult to use in comparable studies. In the quantitative studies, the questionnaires are either poorly described ${ }^{[4,9]}$ or long and time-consuming (a 40-question survey). ${ }^{[10]}$ Richards et al. used an 11-item patient satisfaction questionnaire to compare hospital at home with routine hospital care. ${ }^{[1]}$ However, the validity of that questionnaire was unclear. To our knowledge no appropriate satisfaction questionnaire is available for the old geriatric patient with regard to early follow-up and hospital at home.

In a Danish healthcare setting, length of hospital stay is on average three days in 75+ year's old geriatric patients with acute illness. ${ }^{[3]}$ Even though length of hospital stay is not correlated with patient satisfaction, ${ }^{[12]}$ the transition from hospital to home is a challenge due to shortness of stay. To explore the bridging between hospital and home in order to improve the quality of healthcare, we found it necessary to record the patients' experiences. We developed a patient satisfaction questionnaire based on the subjects that older patients find important during transition from hospital to home. We compared patients who received early follow-up within 24 hours after hospital discharge by a geriatric team with patients who received usual follow-up according to satisfaction as a quantitative measure.

\section{METHODS}

\subsection{Design, population and setting}

This study is a cross-sectorial questionnaire survey based on a quasi-randomized controlled trial conducted in a Danish University Hospital. The quasi-experimental study is a “Triple Aim" quality development project designed to improve care quality, reduce health costs, and increase patient satisfaction (see Figure 1). ${ }^{[3,13]}$ In that study, consecutive admission days were randomized to intervention or control. Admitted eligible patients belonged to the assigned day's strategy. The patients were either allocated to early geriatric follow-up visits within 24 hours after discharge (intervention group) or to usual care (control group) (see Section 2.3). Inclusion criteria were age of 75 years or older, admission to emergency department (ED), assigned to comprehensive geriatric care (CGC), and one of the following diagnoses: pneumonia, chronic obstructive pulmonary disease, delirium, dehydration, urinary tract infection, anemia, constipation, heart failure, or other infection. Exclusion criteria were: state of terminal illness or living outside the municipality. ${ }^{[3]}$

In the questionnaire survey, we consecutively recruited all patients from the quasi-experimental study 2 weeks after discharge during three periods: (1) from September 15 to October 31, 2014, (2) from February 15 to May 15, 2015, and (3) from September 15 to November 15, 2015. We excluded patients registered as dead and cognitively impaired patients (assessed by dementia diagnosis or a statement in the patient's medical chart, that the patient did not know time and place).

Nursing students conducted the survey procedure. A letter with a satisfaction questionnaire (see Section 2.2), witch also included a stamped return envelope, was mailed to all the patients 2-4 weeks after discharge in both the intervention and the control group. If the patient did not respond, the nursing student reminded the patient by phone. If the patient had poor eyesight or was unable to write the student offered to visit the patient and assist in filling out the questionnaire in a face-to-face interview. The students were not aware of to witch group the patients were allocated. The questionnaire contained a box to tick if the questions were read loud and filled out with the patient's answer, or if relatives filled out the questionnaire without any involvement from the patient. All data was entered into the EpiData database.

\subsection{Questionnaire development and validating}

In order to develop the patient satisfaction questionnaire tool, and ensure the validity of its content (the match between questions and the content area which it is intended to assess), ten older cognitively well-functioning patients were interviewed initially. They were all included in the quasi-experimental study. The aim was to explore patients' experience of the transition from hospital to home, and their experience of receiving treatment and care in their own homes. Semistructured interviews were performed based on a qualitative approach. ${ }^{[14]}$ Participants were recruited using purposeful sampling and were interviewed in their own home 2-4 weeks after discharge. An interview-guide was based on relevant literature and included questions concerning the patients' feeling safe when at home again and their ability to engage in usual, daily activities. The interviews lasted 30 minutes on average, and were audiotaped and transcribed verbatim. 


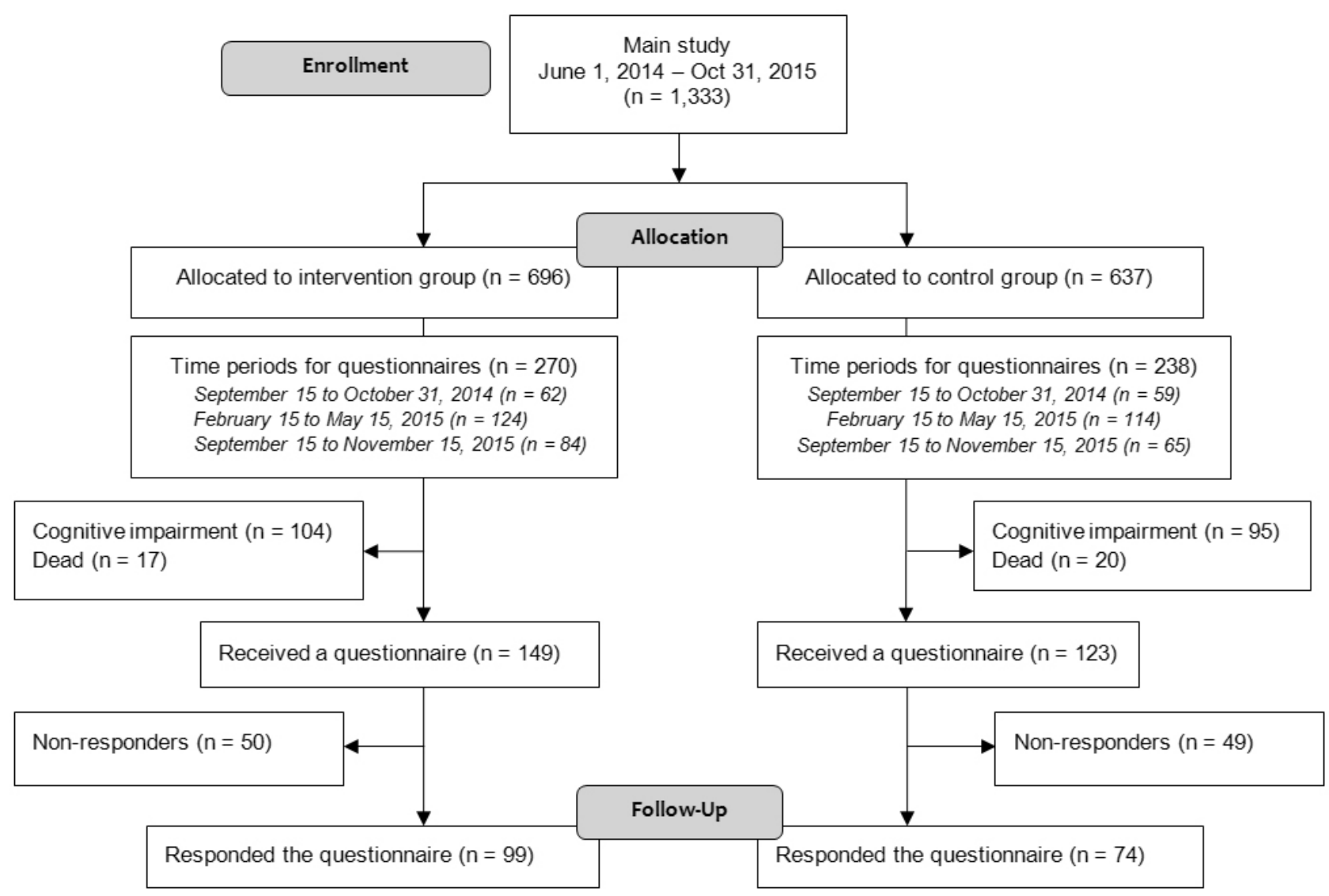

Figure 1. Consort flow diagram

Interview data were analysed using meaning condensation as described by Kvale and Brinkmann. ${ }^{[14]}$ This process implies getting an overall view of the data identifying natural meaning units and identifying and creating themes across interviews. Themes that evolved from the analysis and appeared to be important to the patients were: feeling safe at home, being considered as an equal collaborator, receiving sufficient information, experiencing good communication between the health care professionals (hospital and home care), feeling involved in decisions on care and treatment, and that their relatives were involved and considered as important resources for decision making. Based on this qualitative, explorative analysis, we developed a patient satisfaction questionnaire. Questionnaires were categorised containing the relevant domains from the interviews. Fifteen items were expressed, and a 5-point Likert scale was entered each question.

We mailed the questionnaire to all cognitive well-functioning older patients 2-4 weeks after discharge from hospital. In a pilot study of 10 patients, we found that the answer to one question was often missing ("did you experience failures during hospitalization?"). This may due to difficulties in understanding the meaning of the question. Accordingly, we removed it from the analysis of the completed questionnaires.
In the first 91 completed 14-items questionnaires, the Cronbach's Alpha coefficient was 0.89 which means good internal consistency. ${ }^{[15]}$ Test-retest reliability and criterion validity of the questionnaire were not examined.

\subsection{Intervention and control groups}

In Denmark, the health care system is organized vertically in two sectors: (1) primary health care, run by the municipalities and responsible for nursing homes and home care, and (2) specialist health care including the hospital sector and the general practitioners, run by the regional health authorities. ${ }^{[16]}$ The patients in the intervention group received early geriatric follow-up after discharge. It consists of a cross-sectorial service providing a visit in the patient's home within 24 hours after discharge. The primary visit is performed by a geriatric team consisting of a physicians and a nurse both with geriatric expertise. Further follow-up is tailored according to the patient's needs up to 30 days after discharge. The physician from the geriatric team is held clinically responsibility for patient care in this period. The team is available seven day per week/12 hours per day and 24 hour on-call. The team is able to continue the hospital initiated diagnosing and treatment at home by e.g. comprehensive geriatric assessments, medication review, blood tests, 
subcutaneous fluid therapy, blood transfusions, intravenous antibiotics, rehabilitation, and social challenging tasks. The geriatric team cooperates with the primary health care, which supports the team with observations on e.g. blood pressure, temperature, and administration of antibiotics. The patients in the control group were followed after discharge by their general practitioner. They had access to geriatric services at home as the intervention group - with the exception of the early follow-up visit within the first 24 hours.

\subsection{Statistical analysis}

The baseline characteristics from the main study were appended the questionnaire data. Statistical analyses were performed with Stata software, version 13.0. A $p$-value $\leq .05$ was considered statistically significant.

We analysed the sociodemographic and clinical data by comparing the categorical variables with chi-square test or Fishers' exact test, and the continuous variables with Student's $t$-test to examine if the two groups were similar. Wilcoxon rank sum test was used to compare each answer in the questionnaires from the two groups. The medians are presented with interquartile ranges (IQR). To uncover a difference in the results whether the patients answered the questionnaire themselves, their relatives or the nursing students filled out the questionnaire, a sensitivity analysis was made. Finally, the non-responders' baseline characteristics were compared with the responders' to test for any differences.

\subsection{Ethics}

The Danish Data Protection Agency approved the study (Case no. 1-16-02-474-14). The ten patients who participated in the qualitative interviews gave informed consent. Approval was not required in the main study (Denmark Region Ethical Committee: Case no. 1-10-72-326-13). Patients could decline to respond the questionnaire.

The study was registered at ClinicalTrial gov, Identifier: NCT02664948.

\section{RESULTS}

\subsection{Baseline characteristics}

In the three time periods of the patient satisfaction survey, 508 patients were admitted and fulfilled the inclusion criteria (see Figure 1). Of these, 272 patients (54\%) were cognitively well-functioning and alive 2-4 weeks after discharge. They all received the questionnaire by mail. Of these, 173 patients $(64 \%)$ responded; $66 \%$ from the intervention group and $60 \%$ from the control group $(p=.29)$. Table 1 summarizes the responding patients' demographic characteristics, health status at the time of admission, their needs for personal assistance, and the frequency of contacts with their relatives. The intervention and control groups were comparable on all parameters. Half of the patients were discharged to their home directly from the ED, and the other half was transferred to geriatric wards due to severe illness. The median length of total hospital stay was 2 days for both groups $(p=.98)$. More than half of the patients needed assistance to fill in the questionnaire; $68 \%$ in the intervention group vs. $55 \%$ in the control group $(p=.10)$. In some cases solely the relatives answered and filled out the questionnaire, $22 \%$ in the intervention group and $11 \%$ in the control group $(p=.13)$.

Table 1. Baseline characteristics

\begin{tabular}{|c|c|c|c|}
\hline & $\begin{array}{l}\text { Intervention } \\
(\mathrm{n}=99)\end{array}$ & $\begin{array}{l}\text { Control } \\
(n=74)\end{array}$ & $p$-value \\
\hline Females (\%) & $56(57)$ & $47(63)$ & .35 \\
\hline Mean age $(S D)$ & $87.0(5.6)$ & $86.8(5.4)$ & .81 \\
\hline \multicolumn{4}{|l|}{ Dwelling (\%) } \\
\hline - Own home & $61(61)$ & $47(64)$ & \multirow{4}{*}{.87} \\
\hline - Sheltered housing & $22(22)$ & $13(18)$ & \\
\hline - Nursing home & $12(12)$ & $11(15)$ & \\
\hline - Other & $4(4)$ & $3(4)$ & \\
\hline Living alone (\%) & $64(65)$ & $54(73)$ & .33 \\
\hline \multicolumn{4}{|l|}{ Comorbidity $^{\S}(\%)$} \\
\hline - Low & $27(27)$ & $12(16)$ & \multirow{3}{*}{.39} \\
\hline - Moderate & $42(43)$ & $39(53)$ & \\
\hline - High & $30(30)$ & $23(31)$ & \\
\hline \multicolumn{3}{|l|}{ Diagnoses (\%) } & \multirow{10}{*}{.14} \\
\hline - Pneumonia & $19(19)$ & $8(11)$ & \\
\hline - $\mathrm{COPD}^{\dagger}$ & $4(4)$ & $10(14)$ & \\
\hline - Dehydration & $14(14)$ & $10(14)$ & \\
\hline - Delirium & $6(6)$ & $0(0)$ & \\
\hline - Constipation & $5(5)$ & $3(4)$ & \\
\hline - $\mathrm{CVD}^{\mathrm{f}}$ & $7(7)$ & $4(5)$ & \\
\hline - Anemia & $6(6)$ & $6(8)$ & \\
\hline - Urinary tract infection & $19(19)$ & $18(24)$ & \\
\hline - Other infections & 19 (19) & $15(20)$ & \\
\hline \multicolumn{3}{|l|}{ In contact with relatives $(\%)$} & \multirow{5}{*}{.25} \\
\hline - Daily & $57(58)$ & $46(62)$ & \\
\hline - Weekly & $37(37)$ & $24(32)$ & \\
\hline - Monthly & $2(2)$ & $4(6)$ & \\
\hline - Less or never & $3(3)$ & $0(0)$ & \\
\hline \multicolumn{3}{|l|}{ Home care $(\%)$} & \multirow{5}{*}{.55} \\
\hline - Daily & $56(57)$ & $35(47)$ & \\
\hline - Weekly & $6(6)$ & $3(4)$ & \\
\hline - Every $14^{\text {th }}$ day & $4(4)$ & $5(7)$ & \\
\hline - Never & $13(13)$ & $13(18)$ & \\
\hline
\end{tabular}

The patients who refused to answer the questionnaire were similar to the responders according to the baseline variables except that fewer men were non-responders than women (28\% vs. $41 \%$ ) (see Table 2 ). 
Table 2. Baseline characteristics of responders vs. non-responders

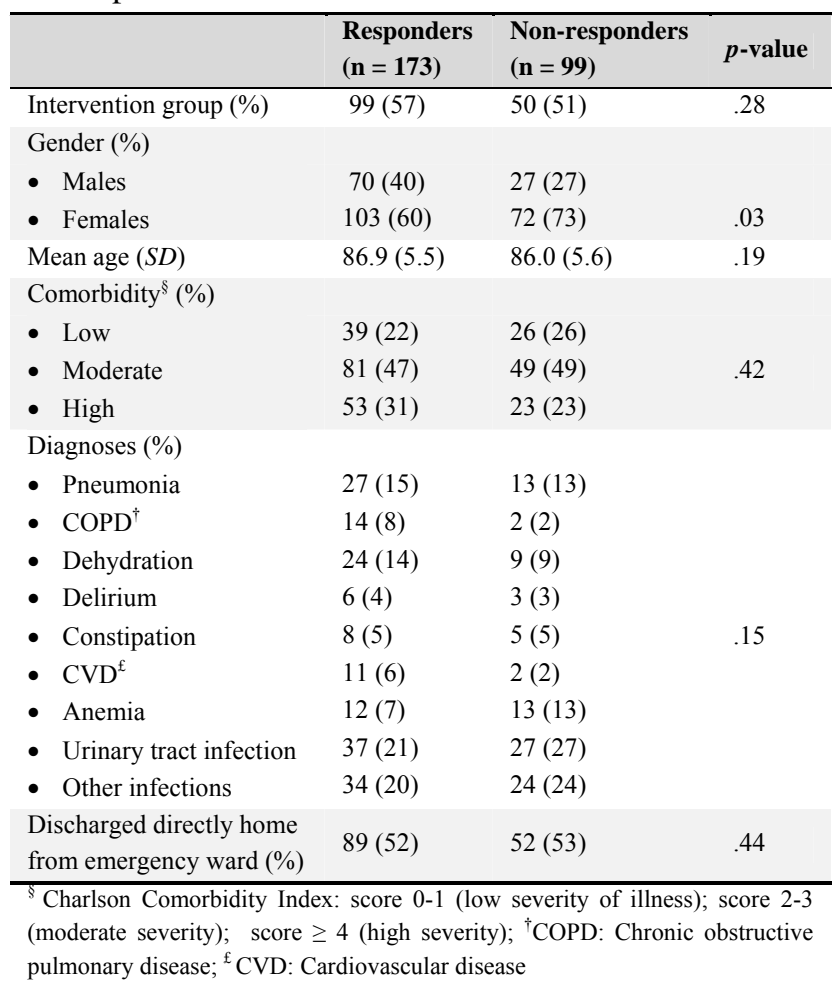

\subsection{Patient satisfaction}

The median sum score for the total questionnaire items was 1.79 (IQR: $1.5-2.4)$ in the intervention group and 1.92 (IQR: 1.4-2.6) in the control group $(p=.39)$. In the intervention group, $89 \%$ of the patients were "satisfied with treatment and care after discharge" compared to $66 \%$ of the patients in the control group, $7 \%$ vs. $24 \%$ were uncertain, and $4 \%$ vs. $10 \%$ disagreed $(p=.003)$. In the question "overall, I was satisfied with the continuity of care at home", $81 \%$ in the intervention group totally or mainly agreed vs. $64 \%$ in the control group, $13 \%$ vs. $19 \%$ were uncertain, and $6 \%$ vs. $17 \%$ disagreed $(p=.05)$ (see Table 3).

Thirty eight percent of the patients did not feel healthy at the time of their response $(p=.62)$. In both groups, $89 \%$ of the patients totally agreed or mainly agreed with the statement "satisfied with treatment and care during hospitalization" ( $p=.76$ ), 5\% were uncertain, and 6\% disagreed. Both groups of patients felt safe at home and involved in the geriatric treatment and care. Eighty-three percent in the intervention group knew whom to contact if they had problems vs. $73 \%$ in the control group $(p=.28)$. The patients also felt that their relatives were involved. Seventy eight percent of the patients were satisfied with the level of the geriatric information during hospital stay and in their home. Seventy four percent of the patients experienced good cooperation between the geriatric team and the home care.
The questionnaires that were filled out solely by the relatives were removed in a subgroup analysis. The difference in satisfaction, when measuring satisfaction with treatment and care after discharge, was even more statistically significant ("I was satisfied with treatment and care after discharge": $p=.002$; "Overall, I was satisfied with continuity of care at home": $p=.01)$.

\section{Discussion}

This study compared the measures of satisfaction in patients receiving early geriatric follow-up with patients receiving usual follow-up after discharge. Generally, all patients were very positive about their experiences during hospitalization. In the two questions regarding specific the continuity of care at home, however; a higher patient satisfaction was found in the patients who received the early geriatric follow-up visit within 24 hours after discharge from the hospital.

\subsection{Other studies}

Rather few studies have examined this area. Similar results were found in studies on "early discharge - hospital at home". In 1998 Richard et al. found that in England most patient responses, according to a 5-point Likert scale of patient satisfaction, are in the top categories in favour of hospital follow-up at home. ${ }^{[11]}$ In another study from England from 1998 it was concluded that patients who are discharged early from hospital after elective surgery and followed at home express greater satisfaction with care than those who remain in hospital. ${ }^{[17]}$ However, in the US in 1999 Naylor et al. did not found a higher patient satisfaction with home follow-up within 48 hours after hospital discharge. The intervention was performed by an experienced practice nurse and compared to standard home care. ${ }^{[9]}$ Our intervention included both a nurse and a physician with geriatric expertise. After discharge, the patients may not feel left alone by this early visit. The patients and their relatives had direct access to the geriatric team (hospital service) if needed. The team continued the hospital assessments, observations, treatments and care in the patient's home with a very short intermission. In an Australian study from 2006, Caplan et al. found that home rehabilitation of frail elderly after 6 days was associated with greater patient satisfaction compared to in-hospital care. ${ }^{[18]}$ In New Zealand, patients being treated for an acute medical problem in their home more often rated their overall satisfaction as "very good" or "excellent" than those in the hospital group. ${ }^{[4]}$ Patients with chronic obstructive airways disease (COPD) were equally satisfied with either hospital at home or inpatient management. However, input from healthcare services can make patients with exacerbation of COPD more able to manage their disease when treated at home. ${ }^{[19]}$ 
Table 3. Patients' satisfaction with treatment and care at hospital and at home expressed at 2-4 weeks after discharge from hospital

\begin{tabular}{|c|c|c|c|}
\hline Questionnaire items & $\begin{array}{l}\text { Intervention-group } \\
\text { median-score }\end{array}$ & $\begin{array}{l}\text { Control-group } \\
\text { median-score }\end{array}$ & $p$-value \\
\hline I am feeling healthy (IQR) & $3(2-4), n=89$ & $3(2-4), n=70$ & .44 \\
\hline I am feeling more healthy now than before discharge from hospital (IQR) & $2(1-4), n=91$ & $2(1-4), n=67$ & .98 \\
\hline I was satisfied with treatment and care during hospitalization (IQR) & $1(1-2), \mathrm{n}=95$ & $1(1-2), n=73$ & .59 \\
\hline I felt safe being discharged to home (IQR) & $1(1-3), n=94$ & $1(1-2), n=73$ & .62 \\
\hline Overall, I was satisfied with the hospitalization (IQR) & $1(1-2), n=94$ & $1(1-2), n=73$ & .70 \\
\hline I was satisfied with treatment and care after discharge (IQR) & $1(1-2), n=94$ & $2(1-3), n=71$ & .003 \\
\hline I felt safe at home after discharge (IQR) & $1(1-2), n=95$ & $1(1-2), n=73$ & .41 \\
\hline Overall, I was satisfied with the continuity of care at home (IQR) & $1(1-2), \mathrm{n}=92$ & $2(1-3), n=69$ & .05 \\
\hline I experienced that the geriatric team and home care cooperated (IQR) & $1(1-2), \mathrm{n}=93$ & $1(1-3), n=70$ & .23 \\
\hline I was involved in the decisions related to my treatment (IQR) & $1(1-3), \mathrm{n}=97$ & $2(1-3), n=68$ & .76 \\
\hline My relatives were involved in the decisions regarding my treatment (IQR) & $1(1-2), \mathrm{n}=95$ & $1(1-2), \mathrm{n}=66$ & .29 \\
\hline I felt that my opinion was important (IQR) & $2(1-3), n=95$ & $2(1-3), n=69$ & .66 \\
\hline I received sufficient information (IQR) & $1(1-2), \mathrm{n}=97$ & $2(1-3), n=71$ & .59 \\
\hline I knew whom to contact if I had questions (IQR) & $1(1-2), n=98$ & $2(1-3), n=70$ & .64 \\
\hline
\end{tabular}

Note. The median are presented with interquartile range on each item in the questionnaire and compared by Wilcoxon ranksum test; score $1=$ totally agree; score 2 = mainly agree; score 3 = neither/nor; score 4 = mainly disagree; score 5 = totally disagree

\subsection{Domains}

The pattern in our study reported higher satisfaction in some domains and not in others. Only few patients were dissatisfied with the geriatric services. Many surveys in the older population seem to report very positive responses. ${ }^{[20]}$ However, health status is an important modifier of patient satisfaction and should be taken into account when interpreting the patient satisfaction data. Satisfaction with hospital care is higher in patients with better self-reported health. In patient with poor to fair health, satisfaction scores peak at age 65 before declining. In patient with good to excellent health, scores peak at age $80 .{ }^{[20]}$ Only $10 \%$ in our responders were less than 80 years old and $79 \%$ had moderate to high severity of illness. Therefore, the high overall satisfaction in our older patients was not expected.

Knowledge of whom to contact after discharge has been described as an important part of older patients' satisfaction with the quality of care. ${ }^{[21,22]}$ Also, lack of communicational systems across the health care sectors negatively affects the older patient's transition between the sectors. It indicates the importance of proper information not only between health care professionals, but also between the health care professional and the older patient. ${ }^{[23]}$ Insufficient information seems to limit the older patient's understanding and feeling of being properly taken care of. ${ }^{[21,22]}$ Several studies report a lack of information continuity between health care sectors, and the lack of information exchange has proven to compromise patient safety. ${ }^{[24,25]}$ The patients who are well-informed about the transferral process express satisfac- tion, feel safe, and are in control of their situation. However, lack of understanding of the information seems to lead to confusion and insecurity in the older patient. ${ }^{[21,22]}$ Clearly, there is a need to establish a communicative relationship with older patients, allowing them to bring forth their questions and worries.

Recent research argues that older patients do want to participate in decision making, but because of the inequity in power between the patient and the professionals, the patients are left in a vulnerable position and may therefore be reluctant to express their preferences. ${ }^{[26-28]}$ Follow-up at home indicates higher levels of equality and the patient's involvement in decision making. ${ }^{[11]}$ Extended support from either family or professionals has been shown to facilitate patient participation and to give older patients a stronger position from which to influence the decisions. ${ }^{[28,29]}$

\subsection{Methodological considerations}

The strength of our study is that a large group of patients participated in spite of their high age and comorbidity burden. We were able to complete the study with a response rate of $64 \%$. Content validity of the questionnaire was high due to the convergent agreement between patients' needs and the domains in the questionnaire. We used both the qualitative and the quantitative research method to strengthen the study. Internal consistency reliability, to estimate how well the 14-items questionnaire reflects the same construct, has yielded good results. The fact that our results are consistent over different time periods demonstrates that the patient sat- 
isfaction tool have valid and significant clinical implication irrespective of medical diagnoses.

However, there were some limitations of this study. In the process of filling out the questionnaire there was a high risk of systematic errors. Selection bias was potential due to the fact that more men than women answered the questionnaires. Furthermore, we assume that the most motivated and positive patients were the responders. Information bias was also possible, since some of the patients may have had problems remembering the exact hospital admission and the relevant events although all the cognitively impaired patients should have been excluded from the survey. Also, the patients who needed our nurse student's assistance to fill out the questionnaire may have responded more positively than those who answered by own hand. There was no difference between the groups' sum scores of the total items. Only two of the 14 questions showed significant differences between the groups. The questionnaire might lack of sensitivity to detect real differences.

We believe that the result from this study is generalizable in all the older patients with acute illness and that the questionnaire is applicable in settings where "early follow-up" and "hospital at home" arrangements are carried out. Unfortunately, we had to exclude $46 \%$ of the patients from the main study due to cognitive impairment and death. One could argue that we should have used the patients' family members, friends, or caregivers as proxy raters. Leff et al. found that family members are more satisfied with treatment and care at home than with the hospital. ${ }^{[10]}$ Similarly, Wilson et al found that caregivers in the primary health care feel that hospital at home does not produce a higher burden of care. ${ }^{[5]}$ The relatives in our study were at least just as satisfied as the patients.

We may not have been able to measure the quality of the service "early geriatric follow-up" after discharge by this patient satisfaction survey; however, the patient's experience of the health care service is important information to secure the patient's influence on the organizational functioning and structure. ${ }^{[30]}$ By healthcare improvements that describe an approach to optimizing health system performance, we need to address several dimensions at the same time; improve care quality, reduce health costs, and increase patient satisfaction. ${ }^{[13]}$

\section{CONCLUSIONS AND PRACTICAL IMPLICA- TIONS}

Nearly all older patients are satisfied with the offered geriatric service both at hospital and at home. However, when older patients receive the service of early geriatric follow-up within 24 hours after discharge they report a higher experienced satisfaction with the geriatric treatment and continuity of care after discharge compared to usual follow-up. This improved satisfaction along with the previous findings of shorter hospital stays, and fewer readmissions contribute to clarify the advantages of an interdisciplinary collaboration with a geriatric nurse and physician immediately after discharge. A validated questionnaire to measure patient satisfaction is usable to compare early geriatric follow-up after hospital discharge with usual follow-up in geriatric patients. However, the lack of test-retest reliability and criterion validity of this questionnaire should be examined in further studies.

\section{ACKNOWLEDGEMENTS}

The authors would like to extend our sincere gratitude to all the patients and their relatives who voluntarily participated in this study. We also thank the nursing students who participated in questionnaire development and collecting the data on patient satisfaction: Heidi Helverskov (medical doctor) and Maria Mogensen, Maria Madsen, Camilla Klinge Knudsen, Line Carstensen, Marie Koldborg Holm, Sofie Amalie Saabye Marland, and Louise Lemming (all nursing students) from VIA University College.

\section{CONFlicts of InTEREST Disclosure}

The authors declare they have no conflicts of interest.

\section{REFERENCES}

[1] Clegg A, Young J, Iliffe S, et al. Frailty in elderly people. Lancet. 2013; 381(9868): 752-762. http://dx.doi.org/10.1016/S01 40-6736 (12) 62167-9

[2] Mesteig M, Helbostad JL, Sletvold O, et al. Unwanted incidents during transition of geriatric patients from hospital to home: a prospective observational study. BMC Health Serv Res. 2010; 10: 1. PMid: 20044945. http://dx.doi.org/10.1186/1472-6963-10-1

[3] Pedersen LH, Gregersen M, Barat I, et al. Early geriatric follow-up after discharge reduces readmission - A quasi-randomised controlled trial. European Geriatric Medicine. 2016. http://dx. doi .org/1 $0.1016 / j$.eurger .2016 .03 .009

[4] Harris R, Ashton T, Broad J, et al. The effectiveness, acceptability and costs of a hospital-at-home service compared with acute hospital care: A randomized controlled trial. J Health Serv Res Policy. 2005; 10(3): 158-166. PMid: 16053592. http://dx.doi.org/10.1258 /1355819054338988

[5] Wilson A, Wynn A, Parker H. Patient and carer satisfaction with 'hos- 
pital at home': quantitative and qualitative results from a randomised controlled trial. 2002; 52(474): 9-13.

[6] McColl E, Jacoby A, Thomas L, et al. Design and use of questionnaires: A review of best practice applicable to surveys of health service staff and patients. Health Technol Assess. 2001; 5(31): 1-256. PMid: 11809125. http://dx.doi.org/10.3310/hta5310

[7] Shepperd S, Doll H, Broad J, et al. Early discharge hospital at home. Cochrane Database of Systematic Reviews. 2008; 1(1). http: //dx.doi.org/10.1002/14651858.CD000356.pub3

[8] Caplan GA, Sulaiman NS, Mangin DA, et al. A meta-analysis of "hospital in the home". Med J Aust. 2012; 197(9): 512-519. PMid: 23121588. http://dx.doi.org/10.5694/mja12.10480

[9] Naylor MD, Brooten D, Campbell R, et al. Comprehensive discharge planning and home follow-up of hospitalized elders: a randomized clinical trial. JAMA. 1999; 281(7): 613-620. PMid: 10029122. http://dx.doi.org/10.1001/jama.281.7.613

[10] Leff B, Burton L, Mader S, et al. Satisfaction with hospital at home care. J Am Geriatr Soc. 2006; 54(9): 1355-1363. PMid: 16970642. http://dx.doi.org/10.1111/j.1532-5415.2006.00855.x

[11] Richards SH, Coast J, Gunnell DJ, et al. Randomised controlled trial comparing effectiveness and acceptability of an early discharge, hospital at home scheme with acute hospital care. BMJ. 1998; 316(7147): 1796-1801. PMid: 9624070. http://dx.doi.org/10.1136/bmj .316 .7147 .1796

[12] Borghans I, Kleefstra SM, Kool RB, et al. Is the length of stay in hospital correlated with patient satisfaction? Int J Qual Health Care. 2012; 24(5): 443-451. PMid: 22789666. http://dx.doi .org/10. 1093/intqhc/mzs037

[13] Institute for Healthcare Improvement. IHI Triple Aim Initiative. 2016. Available from: http://www.ihi.org/engage/initiatives/t ripleaim/Pages/default.aspx

[14] Kvale S, Brinkmann S. Interviews: learning the craft of qualitative research interviewing. 3rd ed. Thousand Oaks, Calif.: Sage Publications; 2014.

[15] Terwee CB, Bot SDM, de Boer MR, et al. Quality criteria were proposed for measurement properties of health status questionnaires. J Clin Epidemiol. 2007; 60(1): 34-42. PMid: 17161752. http://dx.doi.org/10.1016/j.jclinepi.2006.03.012

[16] Danish Ministery of Health. Healthcare. How the Danish Healthcare System works. July 16, 2015. Available from: http://www.sum. $\mathrm{dk} /$ Sundhed.aspx

[17] Shepperd S, Iliffe S. The effectiveness of hospital at home compared with in-patient hospital care: a systematic review (Brief record). 1998; 20(3): 344-350.

[18] Caplan GA, Coconis J, Board N, et al. Does home treatment affect delirium? A randomised controlled trial of rehabilitation of elderly and care at home or usual treatment (The REACH-OUT trial). Age Ageing. 2006; 35(1): 53-60. PMid: 16239239. http: //dx.doi.org/10.1093/ageing/afi206

[19] Wang Y, Haugen T, Steihaug S, et al. Patients with acute exacerbation of chronic obstructive pulmonary disease feel safe when treated at home: a qualitative study. BMC Pulm Med. 2012; 12: 45-2466-1245.

[20] Jaipaul CK, Rosenthal GE. Are older patients more satisfied with hospital care than younger patients? J Gen Intern Med. 2003 Jan; 18(1): 23-30. PMid: 12534760. http://dx.doi.org/10.1046/j $.1525-1497.2003 .20114 . x$

[21] Berglund H, Wilhelmson K, Blomberg S, et al. Older people's views of quality of care: A randomised controlled study of continuum of care. J Clin Nurs. 2013; 22(19-20): 2934-2944. PMid: 23808647. http://dx.doi.org/10.1111/jocn. 12276

[22] Rustad EC, Furnes B, Cronfalk BS, et al. Older patients' experiences during care transition. Patient Preference and Adherence. 2016; 10: 769-779. PMid: 27274204. http://dx.doi.org/10.2147/PPA .S97570

[23] Romoren TI, Torjesen DO, Landmark B. Promoting coordination in Norwegian health care. Int J Integr Care. $2011 \mathrm{Jan} ; 11$ (Spec $10^{t h}$ Anniversary Ed): e127.

[24] Laugaland K, Aase K, Barach P. Interventions to improve patient safety in transitional care-a review of the evidence. Work. 2012; 41(Suppl 1): 2915-2924. PMid: 22317162.

[25] van Walraven C, Taljaard M, Bell CM, et al. A prospective cohort study found that provider and information continuity was low after patient discharge from hospital. J Clin Epidemiol. 2010; 63(9): 10001010. PMid: 20656194. http://dx.doi.org/10.1016/j.jclin epi.2010.01.023

[26] Foss C. Elders and patient participation revisited - a discourse analytic approach to older persons' reflections on patient participation. J Clin Nurs. 2011; 20(13-14): 2014-2022. PMid: 21366738. http://dx.doi.org/10.1111/j.1365-2702.2010.03505.x

[27] Bridges J, Flatley M, Meyer J. Older people's and relatives' experiences in acute care settings: systematic review and synthesis of qualitative studies. Int J Nurs Stud. 2010; 47(1): 89-107. PMid: 19854441. http://dx.doi.org/10.1016/j.ijnurstu.2009.09.009

[28] Bynum JP, Barre L, Reed C, et al. Participation of very old adults in health care decisions. Med Decis Making. 2014; 34(2): 216-230. PMid: 24106235. http://dx.doi.org/10.1177/0272989X135 08008

[29] Roberts K. Exploring participation: older people on discharge from hospital. J Adv Nurs. 2002 Nov; 40(4): 413-420. PMid: 12421400 http://dx.doi.org/10.1046/j.1365-2648.2002.02389.x

[30] Campbell SM, Roland MO, Buetow SA. Defining quality of care. Soc Sci Med. 2000 Dec; 51(11): 1611-1625. http://dx.doi.org /10.1016/S0277-9536(00)00057-5 